\title{
MONIQUE WITTIG: CINCUENTA AÑOS DE LAS GUERRILLERAS (HOMENAJE Y NOTAS SOBRE LA TRADUCCIÓN ESPAÑOLA)
}

\author{
BEATRIZ SUÁREZ BRIONES \\ María Jesús Fariña Busto \\ Universidade de Vigo
}

\begin{abstract}
Este artículo se propone como un homenaje a Les guérillères (1969) de Monique Wittig en su cincuenta aniversario, prestando una atención especial a las secuencias que fueron suprimidas en la única traducción que la obra ha tenido en España hasta el momento (Barcelona, Seix Barral, 1971). Se aporta la traducción de esas secuencias y se considera el papel que pudo tener la censura en su eliminación, así como los efectos de esta eliminación sobre el sentido del texto.
\end{abstract}

PALABRAS Clave: Monique Wittig, Las guerrilleras, traducción española, censura.

Monique Wittig: Fifty Years after Les guérillères (Tribute and Notes on the Spanish Translation)

This article is written as a tribute to Les guérillères (1969) by Monique Wittig on its fiftieth anniversary, and it focuses specially on the sequences that were suppressed in the only translation that the text has had in Spain so far (Barcelona, Seix Barral, 1971). It provides the translation of those sequences and it considers the role that censorship could have in their elimination, as well as the effects of this deletion on the meaning of the text.

KEY WORDS: Monique Wittig, Les guérillères, Spanish translation, censorship.

La figura de Monique Wittig no necesita presentación alguna en el ámbito de los estudios feministas, a pesar de que, en España, si se exceptúa el libro publicado por la editorial Icaria en 2013, Las lesbianas (no) somos mujeres, son inexistentes las monografías sobre su obra. Su vida está inextricablemente unida al activismo y al desarrollo teórico feminista. En las líneas que siguen ofrecemos un breve pero necesario recorrido por su trayectoria antes de centrarnos en las cuestiones relativas a la traducción española de Las guerrilleras que es, en gran medida, lo que aquí nos interesa.

Monique Wittig nace en Alsacia en 1935. Como para la mayoría de su generación, su infancia está marcada por sucesivas migraciones ligadas a la guerra y a la Ocupación: su familia se instala primero en el Franco Condado; después, en Aveyron (Occitania) y, en 1950, cuando Wittig tiene quince años, definitivamente en París, donde la autora se licenciará en Letras por la Sorbona. Con veintinueve años, en 1964, 
asombra al mundo literario de Francia con L'opoponax, novela con la que gana el prestigioso Premio Médicis. Formaban parte del jurado figuras de la talla de Marguerite Duras, Alain Robbe-Grillet y Natalie Sarraute; de ahí partirá su amistad de vida con esta última. Merece la pena echar la vista atrás para leer desde esta distancia temporal la presentación que se hace de Wittig en la contraportada de la edición española, primera y única, que hizo Seix Barral de El opoponax en el año 1969. No tiene desperdicio:

Monique Wittig nació en 1935 en Dannemarie (Ht. Rhin). Es demasiado joven para tener una biografía y su vida ha transcurrido sin saltos bruscos: se licenció en la Sorbona, trabajó en la Biblioteca Nacional de París y trabaja ahora en una casa de edición. Últimamente ha traducido a Marcuse al francés. Nada de extraordinario pues en la vida de esta joven intelectual francesa, excepto su primer libro, publicado en 1964, L'opoponax. (Wittig, 1969a)

Es imposible no subrayar con cierta sorna el "nada de extraordinario pues en la vida de esta joven intelectual”. Traducir a Marcuse debía de ser algo de lo más ordinario entonces. Pero, desde aquí y ahora, y con la ventaja del tiempo transcurrido, por encima de todo sentimos ternura ante lo naíf de la presentación de la persona destinada a ser la dinamita que hizo volar en pedazos el pensamiento feminista sobre el sistema sexo-género, al someterlo a juicio desde la posición visionaria y revolucionaria del pensamiento lesbiano radical.

Todo en Monique Wittig es extraordinario: mientras traducía a Marcuse (L’homme unidimensionnel, vertida desde el inglés con la colaboración del autor y publicada por Minuit en 1968), mantenía un intenso activismo en el movimiento estudiantil y obrero, aunque, decepcionada con la misoginia de ambos, crea, con Antoinette Fouque, Josiane Chanel y Suzanne Fenn, “Les Petites Marguerites”, grupo no mixto de mujeres feministas, maoísta, revolucionario y altermundista. En 1969, el asombro producido por la publicación de L'opoponax se confirma con la aparición de Les guérillères, cuyo medio siglo de vida festejamos en este artículo. Un año más tarde, crea, junto con Margaret Stephenson (Namascar Shaktini), Marcia Rothenburg y su hermana Gille Wittig, el "grupo de Vicennes", cuya pretensión era constituir una asamblea no mixta de mujeres feministas. Escribe en ese momento, para la revista mensual L'Idiot international, el manifiesto fundador del MLF, Movimiento de Liberación de las Mujeres: "Combate por la liberación de la mujer", firmado por las cuatro, aunque la autoría sea, de hecho, de Wittig (sobre esto y sobre la formación del grupo véase Thibaut, 2008; y Shaktini, 2005). El 26 de agosto de ese mismo año, "Les Petites Marguerites", el grupo FMA (Feminismo, Marxismo, Acción) y otras activistas feministas colocan en el Arco de Triunfo una corona de flores en memoria de la esposa del soldado desconocido, acción considerada como gesto fundacional del

168

Lectora, 26 (2020): 167-180. ISSN: 1136-5781 D.O.I.: 10.1344/Lectora2020.26.11 
MLF. ${ }^{1}$ Llevan una pancarta que reza: "Uno de cada dos hombres es una mujer". El acto concluye con la detención de una docena de manifestantes. Existen fotos de esta acción: ${ }^{2}$ en una de ellas, Wittig aparece en primer plano al lado de un gendarme, una cercanía que hace pensar que quizás fue una de las arrestadas, o tal vez nos gusta pensarlo así. Poco tiempo después se produce una ruptura en el MLF entre las feministas que crean el grupo PsychéPo, representado por Antoinette Fouque, y aquellas que se convertirán en las feministas materialistas de las que Monique Wittig formará parte. Aún en 1970, en septiembre, participa en la fundación del grupo feminista radical Feministas Revolucionarias, que en 1971 se convirtió en Gouines Rouges (Bolleras Rojas), el primer grupo de lesbianas formado en París y que reunía a las lesbianas de Feministas Revolucionarias y a las que habían abandonado el Front homosexuel d'action révolutionnaire, FHAR (Frente homosexual para la acción revolucionaria), grupo de liberación homosexual que Wittig había cofundado y del que tuvo que irse, como muchas otras lesbianas, asqueada(s) por su misoginia (para documentarse en mayor profundidad sobre este momento, véase Suárez Briones, 2013).

En 1973 publica Le corps lesbien y, en 1976, con su pareja de vida Sande Zeig, el Brouillon pour un dictionnaire des amantes. Colabora también en la creación de Questions féministes, una de las revistas feministas más importantes de Francia a finales de los setenta y en la que desarrolla "la cuestión lesbiana", cuestión que conllevó tensiones insuperables entre las miembras del comité editorial y desembocó en una ruptura entre ellas y en la desaparición de la revista (Del Olmo Campillo, 2018, 2019). Wittig entra, entonces, a formar parte del comité de la revista norteamericana Feminist Issues y ese mismo año se instala en los Estados Unidos, donde trabaja como profesora invitada en varias universidades. En la década siguiente su actividad se intensifica en todos los frentes: ensayos teóricos (su imprescindible "La pensée straight" entre ellos), conferencias, textos de creación: Virgile, non y Le Voyage sans fin aparecen en 1985 y Paris-la-politique (con narraciones publicadas en revistas desde los años setenta) en 1990. En 1992 se edita en inglés The Straight Mind and Other Essays. Wittig se afinca definitivamente en Tucson, como profesora titular en la Universidad de Arizona, y retoma la edición de Le chantier littéraire, reescritura de su tesis, dirigida por Gérard Genette y defendida en 1985, pero la muerte de Nathalie Sarraute (en 1999), su amiga queridísima y a quien están dedicadas muchas páginas de ese ensayo, le hizo imposible publicarlo entonces. Estaba trabajando de nuevo sobre el texto cuando le sobrevino la muerte, de un ataque al corazón, el 3 de enero de 2003.

\footnotetext{
1 “TODO GESTO ES SUBVERSIÓN”, proclama en Las guerrilleras (Wittig, 1969b: 7).

${ }^{2}$ Ignoramos datos de autoría, lugar de publicación o archivo. Shaktini (2005) recoge tres de estas fotos.
} 
Ya hemos dicho que este año 2019 se celebra el cincuenta aniversario de Les guérillères, publicada en 1969 por las Éditions de Minuit, la misma editorial en la que anteriormente había aparecido L'opoponax (1964) y en la que posteriormente lo harían Le corps lesbien (1973) y Virgile, non (1985). Solo dos años más tarde, en 1971, el libro fue traducido al inglés ${ }^{3}$ y al español. La traducción española, responsabilidad de Josep Elias y Juan Viñoly, ${ }^{4}$ que vio la luz en la editorial Seix Barral, es la única que este libro de Wittig ha tenido en España. Después de medio siglo de andadura, una obra del tamaño literario y político (entendiendo el término en su sentido amplio) de Las guerrilleras merecería una nueva traducción, que le hiciera justicia y la ofreciera en su totalidad, es decir, sin recortes de ningún tipo, algo que no sucede en la de Seix Barral, que presenta algunas lagunas, como hemos enfatizado en otros trabajos (Fariña Busto, 2013, 2015), con lo que esto tiene de mutilación del texto. En este momento, Heckt Libros, un pequeño sello editorial argentino, acaba de editar, en traducción de Natalia Ortiz Maldonado, Guerrilleras, que incluye los párrafos suprimidos en esa única edición española hasta el presente. Hemos tenido noticia de esta traducción mientras redactábamos este artículo, que planteamos como un homenaje al texto wittigiano reflexionando precisamente sobre las ausencias en la edición de Seix Barral y sobre el, creemos, desinterés editorial español por esta y otras obras de la autora.

Como saben quienes frecuentan la obra de Wittig, Las guerrilleras es un libro muy complejo tanto en su fondo como en su forma, como lo son, por otra parte, todos y cada uno de los suyos, complejos al mismo tiempo que verdaderamente excepcionales. Trabajos de diversa índole y con diverso enfoque como los de Bourque (2006), Thomson (2006), Zerilli (2008) o Landry y Leguerrier (2018), así como las observaciones de la propia Wittig (1994), dan cuenta de esta complejidad. Alejada de toda linealidad y apoyada en la fragmentación como recurso significativo, la organización de Las guerrilleras se articula en torno a dos grandes ejes configurados cada uno de ellos por una serie de secuencias. El texto es inclasificable en cuanto al género literario, aunque la propia Wittig lo haya descrito como "un poema épico, un collage" (1994: 116), pues posee tanto de narrativo como de poético y de ensayístico, y juega además con procedimientos gráficos que le aportan una dimensión plástica: la inclusión de tres círculos, que marcan tres partes en el libro, y el empleo de palabras todas en letra mayúscula, siendo estas palabras nombres propios que se agrupan,

\footnotetext{
${ }^{3}$ La edición sale en Londres, en el sello editorial Peter Owen, en traducción de David LeVay. Posteriormente, en 1973 y en 1985, aparecerá, respectivamente, en Nueva York y en Boston.

${ }^{4}$ Josep Elias (1941-1982) y Joan Vinyoli (1914-1984), ambos poetas. Como traductores, Elias lo fue al castellano y Vinyoli tanto al castellano (en este caso firmando Juan Viñoly) como al catalán. En la página de la Associació d'Escriptors en Llengua Catalana, en la entrada correspondiente a uno y otro autor, y entre sus traducciones, no aparece la de Las guerrilleras (“Josep Elias" y "Joan Vinyoli”).
}

170

Lectora, 26 (2020): 167-180. ISSN: 1136-5781 D.O.I.: 10.1344/Lectora2020.26.11 
a manera de mosaicos, en el centro de una página, siempre página derecha. Estos grupos de nombres, que van encabezados y cerrados (principio y final de esa serie) por unas pocas frases que podrían ser consideradas un manifiesto, constituyen uno de los dos ejes arriba mencionados; el otro está integrado por una serie de secuencias o fragmentos narrativo-descriptivo-reflexivos que trazan el desarrollo de una historia de lucha, pero también teórica. Las cinco secuencias completas que se han omitido en la edición española forman parte de esta segunda serie. ${ }^{5}$ Optamos por reproducirlas numeradas y todas juntas a continuación, en traducción nuestra y siguiendo su orden de aparición en el texto de Wittig, para facilitar la referencia a ellas en el comentario posterior:

1. Ellas dicen que exponen sus sexos con objeto de que el sol se refleje en ellos como en un espejo. Dicen que ellos retienen su brillo. Dicen que los pelos del pubis son como una tela de araña que captura los rayos. Se las ve correr a grandes zancadas. Están totalmente iluminadas en su centro, desde los pubis desde los clítoris encapsulados desde las ninfas dobles y plegadas. ${ }^{6} \mathrm{El}$ brillo que despiden cuando se quedan quietas y cuando se ponen de frente hace que los ojos tengan que fijarse en otra parte al no poder sostener la vista. $^{\text {? }}$

2. Ellas dicen que en el feminario ${ }^{8}$ el glande del clítoris y el cuerpo del clítoris son descritos como encapsulados. Allí puede leerse que el prepucio en la base

\footnotetext{
${ }^{5}$ Hemos detectado que faltan también dos frases en otras dos secuencias del libro: "Elles les ont [les oiseaux] dans leur empressement tenus trop étroitement contre elles" (1969b: 22) y "Elles disent le langage que tu parles est fait de mots qui te tuent" (1969b: 162). Por su contenido en el primer caso, $\mathrm{y}$ en el segundo por su brevedad y por formar parte de una serie enumerativa de frases con un significado similar, creemos que su omisión puede obedecer más a descuido que a otro motivo. Sea como sea, la supresión de la segunda oración reduce el énfasis puesto en la enumeración.

${ }^{6}$ Respetamos la puntuación de Wittig, que no emplea comas entre los elementos de esta enumeración. En la traducción del resto de los fragmentos, seguimos el mismo criterio.

7 "Elles disent qu'elles exposent leurs sexes afin que le soleil s'y réfléchisse comme dans un miroir. Elles disent qu'elles retiennent son éclat. Elles disent que les poils du pubis sont comme une toile d'araignée qui capture les rayons. On les voit courir à grandes enjambées. Elles sont tout illuminées en leur milieu, à partir des pubis des clitoris encapuchonnés des nymphes doubles et plissées. L'éclat qu'elles jettent en s'immobilisant et en se tournant de face fait que les yeux se fixent ailleurs n'en pouvant supporter la vue” (Wittig, 1969b: 24). Tendría que aparecer en la página 19 de la edición española.

${ }^{8}$ En su traducción de un artículo de Linda Zerilli sobre Las guerrilleras, en lugar de "feminario", Teresa Arijón decide utilizar el término en femenino, "feminaria" (Zerilli, 2008). Nos parece una propuesta muy interesante, aunque, en este caso, hemos mantenido la versión literal de "le féminaire" del original (como se hace también en la traducción de Seix Barral).
} 
del glande puede moverse a lo largo del órgano provocando una viva sensación de placer. Dicen que el clítoris es un órgano eréctil. También puede leerse que se bifurca a derecha e izquierda, que se dobla, prolongándose en dos cuerpos eréctiles apoyados sobre el hueso púbico. Estos dos cuerpos no son visibles. El conjunto es una zona erógena intensa que irradia todo el sexo convirtiéndolo en un órgano impaciente para el placer. Ellas lo comparan con el mercurio también llamado plata viva por su rapidez en diseminarse, en propagarse, en cambiar de forma. ${ }^{9}$

3. Ellas dicen que el clítoris ha sido comparado con una pepita de cereza, con un brote, con un sésamo descortezado, con una almendra, con una baya de mirto, con un dardo, con el bombín de una cerradura. Dicen que los labios mayores han sido comparados con las dos valvas de una concha. Dicen que la cara oculta de las ninfas ha sido comparada con la púrpura de Sidón, con el coral de los trópicos. Ellas dicen que la ciprina ha sido comparada con el agua del mar yodada salada. ${ }^{10}$

4. Ellas dicen que han encontrado inscripciones en muros de yeso donde las vulvas aparecen dibujadas del mismo modo que las niñas dibujan el sol con múltiples rayos divergentes. Dicen que está escrito que las vulvas son trampas de las mordazas de las tenazas. Dicen que el pubis ha sido comparado con la proa de un barco con su roda con el peine de una concha marina. Dicen que las vulvas han sido comparadas con albaricoques con granadas con higos con rosas con claveles con peonías con margaritas. Ellas dicen que podrían recitarse las comparaciones como una letanía. ${ }^{11}$

\footnotetext{
9 "Elles disent que dans le féminaire le gland du clitoris et le corps du clitoris sont décrits comme encapuchonnés. Il est écrit que le prépuce à la base du gland peut se mouvoir le long de l'organe en provoquant une vive sensation de plaisir. Elles disent que le clitoris est un organe érectile. Il est écrit qu'il bifurque à droite et à gauche, qu'il se coude, se prolongeant dans deux corps érectiles, appuyés contre l'os pubien. Ces deux corps ne sont pas visibles. L'ensemble est une zone érogène intense qui irradie tout le sexe en en faisant un organe impatient au plaisir. Elles le comparent au mercure aussi appelé vif-argent pour sa promptitude à se disséminer, à se propager, à changer de forme" (Wittig, 1969b: 29). Tendría que aparecer en la página 22 de la edición española.

10 "Elles disent que le clitoris a été comparé à un noyau de cerise, à un bourgeon, à une jeune pousse, à un sésame décortiqué, à une amande, à une baie de myrte, à un dard, au canon d'une serrure. Elles disent que les grandes lèvres ont été comparées aux deux valves d'un coquillage. Elles disent que la face cachée des nymphes a été comparée à la pourpre de Sidon, au corail des tropiques. Elles disent que la cyprine a été comparée à l'eau de mer iodée salée” (Wittig, 1969b: 42). Correspondería su presencia en la página 30 de la edición española.

11 “Elles disent qu'elles ont trouvé des inscriptions sur des murs de plâtre où des vulves ont été dessinées comme les enfants dessinent les soleils avec de multiples rayons divergents. Elles disent
}

172

Lectora, 26 (2020): 167-180. ISSN: 1136-5781 D.O.I.: 10.1344/Lectora2020.26.11 
5. Ellas dicen que ellos ponen todo su orgullo en su cola. Ellas se burlan, dicen que ellos querrían una cola muy larga, pero que huirían chillando cada vez que se la pisaran. Ellas se carcajean y se ponen a imitar a algún animal absurdo que tuviera dificultad para desplazarse. Cuando toman un prisionero, lo desnudan y lo hacen correr por las calles gritando, es tu mástil / bastón / palillo batuta / brocha brocheta / vara de plomo. Alguna vez se trata de un cuerpo bello con caderas anchas de piel melosa y sin músculos marcados. Entonces ellas lo toman de la mano y lo acarician para hacerle olvidar todos los malos modos con que lo trataron. ${ }^{12}$

Cuando en 1971 Seix Barral publica Las guerrilleras, Wittig era ya una autora conocida en su catálogo, pues dos años antes, en 1969, se había encargado de editar la traducción, hecha por Caridad Martínez, de L'opoponax (1964). Esta insistencia muestra un interés por la obra de la escritora francesa, muy rompedora desde el principio en cuanto a sus estructuras literarias y a sus temáticas. Seguramente fueron esos dos aspectos los que atrajeron a la editorial barcelonesa, que, con Víctor Seix y Carlos Barral a su frente, ${ }^{13}$ tradujo durante el franquismo, desde los años cincuenta, a un buen número de autorxs y de textos (muchos que la dictadura había puesto bajo sospecha) con la voluntad significativa de contrarrestar los discursos oficiales, pues, como escribe Lucía Montejo en la introducción a su Discurso de autora: género y censura en la narrativa española de posguerra: "La censura no fue solo una práctica consistente en tachar párrafos o suspender importaciones, sino también el medio de hacer circular un tipo de discurso, en definitiva, un tipo de libro" (2010: 19).

qu'il a été écrit que les vulves sont des pièges des étaux des tenailles. Elles disent que le pénil a été comparé à la proue d'un bateau à son étrave au peigne d'un coquillage. Elles disent que les vulves ont été comparées aux abricots aux grenades aux figues aux roses aux oeillets aux pivoines aux marguerites. Elles disent qu'on peut réciter les comparaisons à la façon de litanies" (Wittig, 1969b: 43). La secuencia es correlativa de la anterior.

12 "Elles disent qu'ils mettent tout leur orgueil dans leur queue. Elles se moquent, elles disent que leur queue ils la voudraient longue, mais qu' ils se sauveraient en couinant dès qu'ils marcheraient dessus. Elles s'esclaffent et se mettent à imiter quelque animal saugrenu qui a du mal à se déplacer. Quand elles ont un prisonnier, elles le mettent nu et le font courir dans la rue en criant, elle est ta verge / vergette / batogue baguette / broche brochette / verge de plomb. Quelquefois il s'agit d'un beau corps évasé aux hanches où la peau est miellée où les muscles n'apparaissent pas. Elles le prennent alors par la main et le caressent pour lui faire oublier tous leurs mauvais traitements" (Wittig, 1969b: 152-153). Su falta es notoria en la página 102 de la edición española.

${ }^{13}$ Víctor Seix muere en 1967 y en 1969 Carlos Barral abandona la editorial y funda una nueva empresa, Barral Editores. Información detallada sobre la labor de Carlos Barral como editor puede verse en la tesis doctoral de Juan Ignacio Alonso Campos (2017). 
Hasta 1966 el régimen franquista obligaba a enviar a los censores un ejemplar de toda obra que quisiese ser publicada, fuese una obra original o una traducción. A partir de ese año, con la Ley de Prensa e Imprenta impulsada por Manuel Fraga, esa obligación dejó de ser requisito, lo que no quiere decir que cesase el control sobre las publicaciones, solo que se producía, al menos en apariencia, cierta relajación. Como recuerda Miguel Cruz Hernández (1987), el editor podía elegir entre hacer una consulta previa de la obra, de la que derivaría un informe administrativo positivo o negativo, o imprimirla y, ya una vez impresa, depositarla en el Ministerio de Información y Turismo, cabiendo la posibilidad, en este caso, de que la obra fuese secuestrada y retirada del mercado. Seix Barral adquiere los derechos en lengua castellana para la traducción de El opoponax en la misma fecha en que se promulga esta ley, según consta en el libro cuando se publica en 1969 sin problemas de censura; en palabras de Fernando Larraz: "Not all of the novels suffered the effects of censorship [...] Monique Wittig's L'opoponax (1964; in Spanish, El opoponax, 1969) and some others were allowed with no cuts" (2018: 141). En cuanto a la edición de Las guerrilleras en 1971, no hemos encontrado una documentación similar al respecto. A falta de ella, suponemos que, al igual que El opoponax, fue publicada sin reparos y pudo circular libremente. Pero la obra aparecía expurgada de las cinco secuencias que nos ocupan, lo que indica que, o bien la editorial o bien los propios traductores, determinaron suprimirlas en su totalidad, evidentemente teniendo en cuenta el contexto, pues, aunque su publicación se produce dentro de esos años de aparente debilitamiento censorio que pretendió abrir la Ley de Prensa, no hay que olvidar que la censura pervivió de facto hasta abril de 1977, cuando, ya muerto el dictador, el gobierno de Adolfo Suárez proclamó la libertad de expresión a través del Real decretoley 24/1977; y tampoco conviene subestimar la impronta dejada por el rigor de la férrea censura de las tres décadas anteriores, sobre todo en lo concerniente a la moral sexual tal como la entendía el régimen, lo que hace probable que la editorial prefiriese anticiparse a un rechazo.

Sin duda, a una sociedad tan marcadamente patriarcal como la franquista le resultaría difícil digerir la crítica mordaz a la preocupación de los hombres por su pene, desplegada en la secuencia 5, mucho más procediendo de la pluma de una escritora; también, que la estrecha y rígida moral católica del régimen sentiría heridos sus oídos biempensantes ante cualquier alusión a los órganos sexuales femeninos como órganos de placer (secuencia 2) o a su exposición desenfadada y luminosa (secuencia 1). Es verdad que la vulva y el clítoris se mencionan en otros momentos del libro, en alusiones referidas al valor evocador de ciertos elementos (la $\mathrm{O}$, el 0 y el

174

Lectora, 26 (2020): 167-180. ISSN: 1136-5781 D.O.I.: 10.1344/Lectora2020.26.11 
círculo para la vulva $)^{14}$ o a términos metafóricos con los que una y otro son identificados, ${ }^{15}$ y en esto coinciden con dos de las secuencias eliminadas ( 3 y 4 ); lo que diferencia la descripción de estas últimas es su mayor detallismo y plasticidad y el hecho de que la descripción ocupa la totalidad de ambas secuencias.

En sí mismas, estas supresiones constituyen una mutilación del texto, pero, además, su falta suspende y/o deshace el sentido del fragmento al que siguen. Así, las secuencias 3 y 4 , correlativas dentro de la obra, van precedidas de las dos siguientes:

Ellas dicen que las niñas se entretienen con el feminario. Por ejemplo, en él se habla de tres tipos de ninfas. Las ninfas enanas son triangulares. Las forman, en conjunto, dos pliegues estrechos. Y son invisibles porque los labios las disimulan. Las ninfas medianas tienen el aspecto de una hoja de liliácea. Pueden tener forma de media luna o ser triangulares. Se las ve en toda su extensión, rígidas flexibles burbujeantes. Las ninfas grandes extendidas semejan alas de mariposa. Son enormes triangulares o cuadrangulares, bien visibles.

Ellas dicen que al ser portadoras de vulvas saben lo que las caracteriza. Conocen el monte el empeine el pubis el clítoris las ninfas los cuerpos y los bulbos de la vagina. Dicen que se sienten orgullosas de aquello que durante mucho tiempo fue considerado emblema de la fecundidad y del poder reproductivo de la naturaleza. (Wittig, 1969b: 41-42)

Al eliminarse las dos secuencias posteriores, no solo se produce un recorte en el tejido discursivo, sino también en su significación, pues ambas constituyen expansiones que dan cuenta del modo en que los órganos sexuales femeninos han sido metaforizados social y culturalmente, al eludir nombrarlos de manera directa: "Para hablar de sus sexos, ellas no utilizan más que hipérboles metáforas" (1969b: 93). Frente a ellas, y complementándolas, las secuencias 1 y 2 remarcan el valor de estos órganos (vulva y clítoris) como órganos de placer, presentando, en oposición al lenguaje poético de los otros dos fragmentos, con una mirada casi científica (como también es característico en el lenguaje descriptivo de El cuerpo lesbiano) su forma

\footnotetext{
14 "Ellas dicen que de su canto no sobresale más que una $\mathrm{O}$ continua, lo que hace que ese canto sea para ellas, como todo lo que recuerda a la $\mathrm{O}$, el cero o el círculo, una evocación del anillo vulvar" (Wittig, 1969b: 16). O: "La O, que es el símbolo de la diosa, el símbolo del anillo vulvar" (1969b: 35).

${ }^{15}$ Por ejemplo, en las secuencias que preceden a 3 y 4 (Wittig, 1969b: 41-42), reproducidas más abajo en esta misma página de nuestro artículo, o cuando se dice que los pelos del pubis han sido comparados con el vellocino de oro (1969b: 60) o que la vulva lo ha sido con todo tipo de pájaros (1969b: 60) o con otros símbolos (1969b: 86).
} 
y funcionamiento. ${ }^{16}$ Unos y otros fragmentos destacan, sin embargo, la necesidad de nombrar, de no silenciar, algo que las sociedades hacen permanentemente buscando dejar fuera de escena todo aquello que les molesta o les exaspera. Para las sociedades patriarcales el cuerpo de las mujeres y su placer ha sido siempre objeto de violencia, motivo de discordia y fuente de desagrado; y la negación y el ocultamiento es una violencia más, añadida a las otras. Precisamente por ello, para la escritora Monique Wittig, que buscó con verdadero empeño (y lo logró) la creación de una obra nueva, que funcionase como un "caballo de Troya" ${ }^{17}$ tanto dentro de su contexto cultural como dentro de su contexto histórico-literario, la importancia de nombrar y de cómo hacerlo constituyó una obsesión que recorre todas sus obras de ficción y todos sus textos ensayísticos.

En Las guerrilleras estas descripciones de las ninfas, del clítoris y de la vulva, recogidas en los feminarios, corresponden a un momento en que era necesario designarlos, el momento anterior a la batalla final, cuando aquellas caracterizadas por poseer vulva ${ }^{18}$ eran esclavas del sistema y estaban desterradas del mundo de los signos. ${ }^{19}$ Pero esos feminarios, que poseen algunas características similares a las del formato de la propia obra, ${ }^{20}$ no tienen en el presente más valor que el de servir de entretenimiento a las niñas, si bien, a través de la figura retórica de la preterición (a cuya frecuencia en Las guerrilleras alude Wittig en sus observaciones sobre el libro) se nombra aquello que no querría nombrarse. En este contexto, a través del recurso retórico, se trae al presente la memoria del pasado. Así lo expresa la escritora:

\footnotetext{
16 En "Quelques remarques sur Les Guérillères", Wittig señala: "L'accent est mis sur les termes techniques, quand besoin est. Par exemple les termes anatomiques qui décrivent les organes sexuels sont prélevés de manuels destinés à l'Ecole de médecine” (1994: 119).

${ }^{17}$ Es expresión e idea de Monique Wittig. Véase "El caballo de Troya” (traducción española en El pensamiento heterosexual y otros ensayos, Wittig, 2006: 95-102) y Le chantier littéraire (Wittig, 2010).

18 "Ellas dicen que al ser portadoras de vulvas saben lo que las caracteriza” (Wittig, 1969b: 41).

19 "Ellas dicen, desgraciada, ellos te expulsaron del mundo de los signos y, sin embargo, te dieron nombres, ellos te han llamado esclava, a ti infeliz esclava [...] Ellas dicen, el lenguaje que tú hablas está hecho de signos que, propiamente hablando, designan aquello de lo que ellos se apropiaron. Aquello de lo que no han podido apoderarse [...] no aparece en el lenguaje que hablas. Eso se manifiesta justamente en el intervalo que los dominadores no han podido rellenar con sus palabras de propietarios y poseedores, eso se puede en la laguna, en todo aquello que no posee la continuidad de sus discursos, en el cero, la $\mathrm{O}$, el círculo perfecto que inventas para aprisionarlos y vencerlos" (1969b: 162, 164).

20 "Cuando se hojea, el feminario presenta numerosas páginas en blanco sobre las cuales ellas escriben en algunas ocasiones. En lo esencial, el libro contiene páginas con palabras escritas en mayúsculas en número variable" (1969b: 17).
}

176

Lectora, 26 (2020): 167-180. ISSN: 1136-5781 D.O.I.: 10.1344/Lectora2020.26.11 
No hay litotes en Las guerrilleras. A cambio, encuentro numerosas pretericiones, sobre todo en la segunda parte, como esta: "Ellas no dicen que las vulvas son como soles negros en la noche brillante" ( $L G, 81)$. O: "Ellas no dicen que las vulvas en sus formas elípticas pueden ser comparadas con soles, con planetas, con galaxias incontables" (86). Es un modo irónico de anular los feminarios de la primera parte. Estos feminarios ambiguos donde se hace un repertorio de todos los términos con que son descritas las vulvas ya no sirven ahora, en la segunda parte, más que para informar y divertir a las niñas. (Wittig, 1994: 120)

Las portadoras de vulvas serían las mujeres (probablemente habría que situar la afirmación entre interrogantes), pero mujer es una categoría que, para Wittig, solo tiene sentido dentro del régimen político de la heterosexualidad, de ahí que evite emplear el término y de ahí el malestar que le provocó, como es bien conocido, la traducción de Les guérillères al inglés, en la que el plural colectivo "elles" fue vertido como "the women" (Wittig, 2006: 113). Mujer, mujeres, no obstante, sí aparece en Las guerrilleras, en su tercera parte, última en el discurso pero primera en el tiempo de la historia, pues es el comienzo de la misma. Era el tiempo del combate, el momento que “concierne a la guerra, o mejor guerrilla, entre ellas y ellos" (Wittig, 1994: 119, énfasis en el original).21 Una lucha entre "ellas" y "ellos" que en el discurso de las secuencias de esta parte de la obra presenta también notables deficiencias en la traducción española, pues en algunos momentos resulta equívoco quiénes están ejecutando las acciones, ellas o ellos. Donde no hay confusión posible en el texto de Wittig, se produce, en cambio, en su traducción.

Una traducción defectuosa acaba siendo una fuente de errores; cuando, además, se trata de una traducción que ha mutilado un texto, las consecuencias son mayores. Esto ha pasado con la traducción española de Las guerrilleras, traducción que seguramente ha sido, en el ámbito hispánico, un texto más usado que el propio original, incluso en el campo de la investigación. No puede negarse el mérito y la valentía de la editorial Seix Barral al traducir este libro de Wittig (verdaderamente explosivo en cuanto a su temática) solo dos años después de su publicación original y estando aún España bajo la dictadura de Franco. Lo lamentable es que las ausencias de esa traducción nunca fueran enmendadas y que ninguna otra editorial se haya vuelto a interesar por esta ni por el resto de las obras de Wittig. Porque ni El opoponax ni Las guerrilleras volvieron a tener una traducción en España, ni en español (Las

\footnotetext{
${ }^{21}$ Leemos, por ejemplo: "Ellas dicen, es una equivocación imaginar que yo, mujer, hablaré violentamente contra los hombres. Pero es preciso comenzar, como algo completamente nuevo, la danza en círculo golpeando cada paso contra el suelo. Ellas dicen, dad dos saltos aplaudiendo. Golpeemos el suelo poderosas, oh mujeres" (Wittig, 1969b: 142).
} 
guerrilleras la tiene ahora, en versión rioplatense, en la que acaba de sacar Hekht Libros en Argentina), y una suerte parecida vive el resto de los textos de ficción de la autora: El cuerpo lesbiano, de 1973, salió en 1977 en la editorial Pretextos en traducción de Nuria Pérez de Lara, y el Borrador para un diccionario de las amantes, escrito con Sande Zeig y publicado en 1976, lo hizo en Lumen en traducción de Cristina Peri Rossi en 1981. En cuanto a su obra teatral, la revista Lectora publicó en 2004, en su número 10, El viaje sin fin en traducción de María Jesús Fariña Busto, pero Virgile, non (1985) carece hasta la fecha de una traducción al español, como sucede también con los relatos de Paris-la-politique (1985) y parte de la obra ensayística.

Tal vez cabe entender que en aquel contexto de la dictadura franquista, moribunda pero todavía viva, el texto de Las guerrilleras fuese recortado (en el sentido que hemos visto); también que, incluso en ambientes progresistas dentro de aquel mismo contexto, temas relativos a la política sexual fuesen desdeñados o enfrentados con reticencias, como testimonia Oliva Blanco en una elocuente anécdota a propósito precisamente de un artículo suyo sobre Las guerrilleras:

En los años 70 algunos de los más preclaros representantes de la modernidad de la Facultad de Filosofía y Letras de Oviedo hervían de fervor semiótico jurando por Kristeva, Barthes, etc., y salmodiando los artículos de Tel Quel, lo cual no fue óbice para que este artículo sobre la autora que nos ocupa en el que se ponen de manifiesto las relaciones entre lenguaje y política sexual fuera considerado no digno de ser publicado en una revista de cuyo nombre no me acuerdo. (Blanco, 2004: 128)

Lo que no cabe entender de ningún modo es que esa edición cercenada de Las guerrilleras sea todavía la única disponible en España y por la que se sigue citando. Creemos que es hora, y es tarde, de que la poderosa escritora de ficción que es Monique Wittig, además de pensadora imprescindible dentro de la teoría feminista y lesbiana (lo que viene a ser lo mismo que una pensadora imprescindible dentro de la teoría contemporánea), esté representada en español como se merece.

\section{REFERENCIAS BIBLIOGRÁFICAS}

Alonso Campos, Juan Ignacio (2017), Carlos Barral. La edición en la España franquista, Tesis doctoral, Alcalá de Henares, Universidad de Alcalá de Henares, 15/03/2017. <http://hdl.handle.net/10017/37287>

Blanco Corujo, Oliva (2004), "Monique Wittig: réquiem por una guerrillera", Clepsydra, 3: 127-132.

178

Lectora, 26 (2020): 167-180. ISSN: 1136-5781 D.O.I.: 10.1344/Lectora2020.26.11 
Bourque, Dominique (2006), Écrire l'inter-dit. La subversión formelle dans l'oeuvre de Monique Wittig, París, L'Harmattan.

Cruz Hernández, Miguel (1987), "Del deterioro al desmantelamiento. Los últimos años de la censura de libros”, Diálogos hispánicos de Amsterdam, 5: 41-56.

Del Olmo Campillo, Gemma (2018), "Cruce de fronteras. Relevancia de la sexualidad en el feminismo”, Feminismo/s, 31: 65-81.

-(2019), “El desafío violeta. Un camino de libertad", Investigaciones feministas, 10 (1): 45-59.

Fariña Busto, María Jesús (2013), "Haciendo cosas con el lenguaje. La escritora en su taller", Las lesbianas (no) somos mujeres. En torno a Monique Wittig, Beatriz Suárez Briones (ed.), Barcelona, Icaria: 117-147.

-(2015), "Entre guerrilleras y andariegas: de Monique Wittig a Albalucía Ángel", Ambigua. Revista de investigaciones sobre género y estudios culturales, 2: 58-73.

"Joan Vinyoli", Associació d'Escriptors en Llengua Catalana, 10/12/2019. $<$ https://www.escriptors.cat/autors/vinyolij>

“Josep Elias", Associació d'Escriptors en Llengua Catalana, 10/12/2019. $<$ https://www.escriptors.cat/autors/eliasj>

Landry, Iraïs y Louis-Thomas Leguerrier (2018), “Ce qui est à écrire violence’: montage et dialectique dans Les guérillères de Monique Wittig", Études françaises, 54 (1): 117-134.

Larraz, Fernando (2018), "Gender, Translation and Censorship in Seix Barral's 'Biblioteca Breve' and 'Biblioteca Formentor' (1955-1975)”, Foreign Women Authors under Fascism and Francoism: Gender, Translation and Censorship, Pilar Godayol y Annarita Taronna (eds.), Newcastle, Cambridge Scholars Publishing: 126-145.

Montejo, Lucía (2010), Discurso de autora: género y censura en la narrativa española de posguerra, Madrid, UNED.

Shaktini, Namascar (2005), "Introduction to 'For a Women's Liberation Movement", On Monique Wittig. Theoretical, Political, and Literary Essays, Namascar Shaktini (ed.), Urbana \& Chicago, University of Illinois Press: 15-20.

Suárez Briones, Beatriz (2013), “Cuando las lesbianas éramos mujeres”, Las lesbianas (no) somos mujeres. En torno a Monique Wittig, Beatriz Suárez Briones (ed.), Barcelona, Icaria: 15-50.

Thibaut, Josy (2008), “Entretien. Monique Wittig raconte...”, ProChoix, 46: 63-76.

Thomson, Clive (2006), "Dire l'alterité: Les guérillères de Monique Wittig”, Acta poética, 27 (1): 273-291.

Wittig, Monique (1969a), El opoponax, Caridad Martínez (trad.), Barcelona, Seix Barral. 
—(1969b), Les guérillères, París, Editions de Minuit.

-(1971), Las guerrilleras, Josep Elías y Juan Viñoly (trads.), Barcelona, Seix Barral.

-(1994), "Quelques remarques sur Les guérillères", L'esprit créateur, 34 (4): 116-122.

-(2006), El pensamiento heterosexual y otros ensayos, Javier Sáez y Paco Vidarte (trads.), Madrid \& Barcelona, Egales.

-(2010), Le chantier littéraire, Donnemarie-Dontilly, Éditions iXe \& Lyon, Presses Universitaires de Lyon.

Zerilli, Linda (2008), El feminismo y el abismo de la libertad, Buenos Aires, Fondo de Cultura Económica.

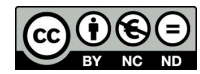

